\title{
Conhecimentos mobilizados por professoras dos anos iniciais na elaboração de histórias infantis com conteúdos matemáticos
}

\section{Knowledge mobilized by teachers in the early years of elementary school to create children's stories with mathematical content}

\author{
Reginaldo Fernando Carneiro* \\ Ana Paula Gestoso de Souza**
}

\begin{abstract}
Resumo: Este artigo tem como objetivo identificar e analisar os conhecimentos mobilizados por professoras dos anos iniciais do Ensino Fundamental, ao elaborarem histórias infantis com conteúdos matemáticos. A pesquisa desenvolvida aproxima-se da vertente de pesquisa participante, e o local de investigação foi um curso de curta duração oferecido, pelos autores deste texto, em um seminário de Educação Matemática para professores dos anos iniciais do Ensino Fundamental. Os instrumentos usados para a produção dos dados foram o áudio, o vídeo, o diário de campo e os registros produzidos pelas professoras. Os resultados evidenciaram que as professoras mobilizaram seus conhecimentos do conteúdo e seu conhecimento pedagógico do conteúdo, ao buscarem solucionar os diferentes problemas propostos e, principalmente, ao elaborarem histórias infantis com conteúdo matemático.
\end{abstract}

Palavras-chave: Ensino de matemática. Conhecimentos docentes. Histórias infantis.

\begin{abstract}
This paper aims to identify and analyze the knowledge mobilized by teachers in the early years of elementary school to create children's stories with mathematical content. The research developed leans towards the participant research, and the locus was a short-duration course offered by the authors in a seminar of mathematical education for teachers in the early years of elementary school. The data collection tools were audio and video recordings, field diary and registers produced by the teachers. Results revealed that the teachers mobilized their knowledge of the content and their pedagogical knowledge in order to solve the different problems proposed and, mainly, to create children's stories with mathematical content.
\end{abstract}

Keywords: Mathematics teaching. Teachers' knowledge. Children's stories.

\footnotetext{
* Doutorando em Educação da Universidade Federal de São Carlos. E-mail: <reginaldo_carneiro@yahoo. com.br>

** Doutoranda em Educação e professora substituta da Universidade Federal de São Carlos. E-mail: <ana_ gestoso@yahoo.com.br>
} 


\section{Introdução}

As relações possíveis entre língua materna e matemática são indicadas por diversos autores como uma das possibilidades para a aprendizagem efetiva da matemática, na medida em que auxiliam os alunos a compreenderemos enunciados dos problemas, a construírem conceitos e a entenderem a linguagem matemática. Podem, ainda,estimular o hábito da leitura (GÓMEZ-GRANELL, 1997; MACHADO, 1991; SILVA, 2003; SMOLE; DINIZ, 2001; SOUZA, 2008).

Para que as possibilidades advindas dessa integração sejam exploradas, objetivando o desenvolvimento efetivo da aprendizagem,também consideramos importante voltar o olhar para o professor e investigar a mobilização de seus conhecimentos quando entram em contato com propostas que possibilitam a articulação entre língua materna e matemática.

Considerando esse cenário, este artigo busca identificar e analisar os conhecimentos mobilizados por professoras dos anos iniciais do Ensino Fundamental, ao elaborarem histórias infantis com conteúdo matemáticos.

É importante apontar que o conceito de mobilização aqui compreendido não se refere ao sentido de motivação. De acordo com Charlot (2000), a mobilização implica uma dinâmica interna de movimento que proporciona o engajamento do sujeito em uma atividade, por conta da existência de um desejo, de um sentido, de um valor na atividade a ser realizada. Para Charlot (2000, p. 82), "o desejo é a mola da mobilização e, portanto, da atividade; não de um desejo nu, mas sim, o desejo de um sujeito 'engajado' no mundo em relação com os outros e com ele mesmo".

Dessa maneira, o professor se coloca em busca de um objetivo que pode ser alcançado de diferentes modos. Nessa dinâmica, ele se mobiliza, busca recursos para isso e, dessa forma, ocorre aprendizagem.

Os sujeitos deste estudo foram 24 professoras dos anos iniciais do Ensino Fundamental que participaram de um curso de curta duração denominado Chapeuzinho Vermelho, Lobo e Frações: histórias nas aulas de matemática, oferecido pelos autores deste texto no Seminário de Histórias e Investigações em/nas Aulas de Matemática que é organizado pelo Grupo de Sábado da Universidade Estadual de Campinas. O curso teve como objetivo apresentar e discutir as possibilidades de uma relação de complementaridade entre língua materna e matemática, demonstrando que essa conexão contribui para a formação de leitores fluentes, de sujeitos que conhecem e compreendem a linguagem, os conceitos e as ideias matemáticas e podem utilizá-los a partir de diferentes instrumentos e estratégias para solucionar problemas. 
Por meio dos dados apresentados e discutidos neste artigo, referentes aos registros orais e escritos produzidos pelas participantes do curso, buscamos investigar os conhecimentos mobilizados ao se envolverem em um processo formativo que visou articular práticas de leitura, escrita e matemática.

\section{Mobilizando conhecimentos na conexão entre matemática e histórias infantis}

Neste trabalho, dirigimos nosso olhar para o professor e ressaltamos a ideia de que,ao considerar as potencialidades da conexão entre histórias infantis e conteúdo matemático,ele precisa refletir sobre a língua materna (considerando a diversidade de gêneros textuais), o conteúdo matemático e sua linguagem específica; sobre o registro pictórico e o registro gráfico, entre outros elementos, o que exige do docente um processo de raciocínio complexo e uma ampla base de conhecimento. Essas reflexões são marcadas por incertezas, reflexões, contestações, descobertas, tensões,enfim, por desconstruções e reconstruções de conhecimentos, possibilitando que o professor busque estabelecer conexões entre os conhecimentos teóricos e a prática pedagógica, entre os conteúdos e as metodologias de ensino, os objetivos e as características dos alunos.

Assim sendo, ao buscar, neste texto, identificar e analisar os conhecimentos mobilizados por professoras dos anos iniciais do Ensino Fundamental no estudo sobre a referida abordagem metodológica e suas potencialidades e na elaboração histórias infantis com conteúdo matemáticos, o pano de fundo das análises realizadas enfoca a ideia de base de conhecimento de Shulman e seus colaboradores (SHULMAN, 2004).

A base de conhecimentos para ensinar envolve conhecimentos de diferentes tipos e origens, compreensões, habilidades e disposições, que possibilitam que o docente desenvolva situações de ensino e aprendizagem em diferentes contextos educacionais, níveis e modalidades de ensino e áreas de conhecimento (SHULMAN, 2004).

Este autor descreveu os elementos que compõem os diversos conhecimentos a que o docente recorre durante o processo de ensino e de aprendizagem: conhecimento do conteúdo, conhecimento pedagógico, conhecimento do currículo, conhecimento pedagógico do conteúdo, conhecimento dos alunos e suas características, conhecimento dos contextos educacionais e conhecimentos dos fins educacionais.

Diante das ideias de Shulman e seus colaboradores, Mizukami (2004) enfatiza que essas categorias podem ser agrupadas em: conhecimento do conteúdo específico, conhecimento pedagógico geral e conhecimento pedagógico do conteúdo. 
O conhecimento do conteúdo específico consiste na compreensão de fatos, conceitos, processos e procedimentos de uma área específica (MIZUKAMI, 2004). Shulman (2004) afirma que é fundamental que o docente conheça os conteúdos específicos das disciplinas, suas estruturas sintáticas e substantivas, seu processo de construção e seu uso. Para o autor, é importante que os professores compreendam "o que" e "o porquê" dos conhecimentos, dos fenômenos e dos saberes. Ou seja, não é suficiente que o docente saiba definir conceitos, mas ele deve também conhecer a estrutura de determinada área de conhecimento, saber as formas de organização de seus conteúdos, compreender por que determinados conceitos são aceitos cientificamente e outros não, conhecer a importância e as relações que pode haver entre ele se com outras áreas do conhecimento.

A categoria conhecimento pedagógico geral "transcende uma área específica” (MIZUKAMI, 2004, p. 9), pois envolve os conhecimentos sobre os alunos, as teorias sobre os processos de ensino e de aprendizagem, a familiaridade com os contextos, os fins educacionais, as políticas públicas, os programas educacionais, os fundamentos históricos e filosóficos da educação, as diferentes metodologias de ensino, as formas como as matérias podem ser abordadas pelos livros didáticos, pelas propostas curriculares, pelos softwares etc.

A inter-relação entre os conhecimentos pedagógicos e os dos conteúdos resulta na categoria conhecimento pedagógico do conteúdo, que, para Shulman (2004), envolve os saberes do docente acerca de como ensinar um conteúdo. Para o autor, é fundamental que o professor, além de conhecer o conteúdo específico, saiba utilizar os diferentes modos de representação de um conceito e/ou ideia, como analogias, exemplos, explicações, ilustrações etc.; tenha conhecimentos sobre como os alunos aprendem determinados conteúdos, as dificuldades que enfrentam nesse processo e os conhecimentos prévios dos estudantes acerca dos assuntos e tópicos ensinados; e conheça os aspectos que facilitam e/ou dificultam a compreensão de um conteúdo.

Esses conhecimentos podem ser mobilizados durante a formação do professor, para que ele utilize, em sua prática, a leitura e a escrita no trabalho com conteúdos matemáticos, de forma a possibilitar o que foi evidenciado por Passos; Oliveira e Gama (2007), em seu estudo sobre as potencialidades formativas docentes da conexão entre matemática e histórias infantis. Destacam que essa metodologia é uma

nova forma de abordar a temática de uma área do conhecimento integrada a uma história. Essa abordagem do conteúdo desloca a prática docente com esse conteúdo da atitude de passar o ponto, ensinar um conjunto de regras previamente formulado, para a atitude inquieta da pergunta, do conflito narrativo que leva à reflexão, à aposta na postura de descobrir a matemática mais que na postura de ensinar a matemática que se conhece. (PASSOS; OLIVEIRA; GAMA, 2007, p. 3). 
Em outras palavras, ao abordar conteúdos matemáticos conectados a práticas de leitura e escrita, o professor pode desvencilhar-se de uma postura autoritária, que não permite ao aluno expor seus conhecimentos e seu raciocínio. Além disso, a articulação entre matemática e práticas de leitura e escrita possibilita a criação de situações de ensino que favoreçam a exploração das relações existentes entre a língua materna e a matemática.

A partir de um ensino que conecte matemática e práticas de leitura e escrita, o aluno poderá ter outra visão do conhecimento, que dispensa a tradicional separação das disciplinas, à medida que essa conexão permite a reflexão e/ou o diálogo sobre os elementos, os aspectos, as ideias, os conceitos matemáticos e outras áreas do conhecimento, bem como sobre as diferentes visões de mundo presentes nos diversos gêneros textuais. Ler possibilita entrar em contato com a realidade, relacionar-se com o mundo, encontrar informações e ampliar os conhecimentos.

Diversos estudos (CAREY, 1992; GAILEY, 1993; KLIMAN; RICHARDS, 1992; SILVA, 2003; WELCHMAN-TISCHER, 1992), após investigarem práticas de ensino e aprendizagem que articulam matemática, leitura e escrita de diferentes gêneros textuais ou apontam possíveis situações docentes envolvendo essa conexão, destacaram as potencialidades dessa articulação.

Welchman-Tischer (1992) relata que existem várias formas de usar histórias infantis para ensinar matemática: promover um contexto para desenvolver atividades que incluam conceitos matemáticos; introduzir o uso de materiais manipuláveis que posteriormente possam ser utilizados de formas variadas, sem envolver uma história; mostrar experiências matemáticas criativas para as crianças; organizar um espaço para trabalhar com problemas; apresentar aos alunos noções de um conceito ou habilidade matemática, a princípio sem o formalismo desse conhecimento, para, posteriormente, desenvolver, explicar e/ou rever esses conceitos ou habilidades matemáticas.

Silva (2003) enfatiza que desenvolver uma prática educativa que articule leitura, escrita e conteúdos matemáticos contribui para a superação de uma visão compartimentada das disciplinas e do ensino, ou seja, propicia que sejam percebidas as relações entre as disciplinas. Para tanto, é fundamental que o professor valorize e incentive a compreensão do texto literário e estabeleça as relações entre língua materna e linguagem matemática. Assim, para o autor, as narrativas não serão utilizadas simplesmente como um ponto de partida, mas, sim, em conexão real com outras áreas do conhecimento.

Esses estudos e outros, como, por exemplo, Carneiro e Passos (2007), Neuenfeldt (2006) e Souza (2008), apontam que desenvolver um ensino que aborde práticas de leitura, escrita e matemática é uma alternativa metodológica 
repleta de possibilidades, pois contribui para a formação de alunos leitores que se apropriam da leitura enquanto prática social, capazes de utilizar os elementos necessários para compreender um texto e, por meio dessa compreensão, podem refletir sobre a realidade em que vivem, compartilhar essa realidade e conhecer a si mesmos e aos outros. Contribui ainda para que os alunos se tornem conhecedores da linguagem, dos conceitos e das ideias matemáticas, saibam utilizar diferentes estratégias para resolver problemas, elaborando e testando hipóteses, e relacionem suas experiências ao saber matemático.

Tomando em consideração esses pressupostos, a seguir dirigiremos nosso olhar para a metodologia e os procedimentos metodológicos utilizados na formação do professor, com o objetivo de integrar à sua prática de sala de aula a conexão entre a língua materna e a matemática.

\section{Metodologia e procedimentos metodológicos}

A investigação desenvolvida aproxima-se da vertente de pesquisa participante - PP, pois considera alguns dos elementos dessa metodologia de investigação. Embora haja certa pluralidade na definição das características da pesquisa participante, apoiamo-nos em Demo (1984), que aponta características específicas para esse tipo de pesquisa: defende determinada opção política; apresentase como um modo de descobrir e manipular a realidade conjuntamente com a comunidade; volta-se para um compromisso político; tende à fusão da relação sujeito-objeto de pesquisa; fundamenta-se no critério da prática. Segundo esse autor, a PP tem o mérito de incorporar à investigação a prática e a tomada de posição política, configurando-se como uma alternativa metodológica.

O presente estudo - realizado a partir do curso Chapenzinho Vermelho, Lobo e Frações: histórias nas aulas de matemática, já referido linhas acima - aproxima-se de uma PP, em razão de seu caráter prático e de intervenção. A relação entre pesquisador, sujeitos e objeto possibilitou focalizar a dimensão prática e possíveis elementos para sua transformação, sem negligenciar o rigor teórico-metodológico.

Em um primeiro momento, realizamos uma discussão sobre o ensino da matemática na educação atual, as possibilidades de uma relação de complementaridade entre língua materna e matemática e as potencialidades da utilização dessa relação de integração no ensino e na aprendizagem da matemática, enfocando a resolução de problemas de diferentes tipos: problemas sem solução, com mais de uma solução, com excesso de dados, problemas de lógica, de estratégia, entre outros, e o uso de histórias infantis.

Posteriormente, propusemos atividades de ensino baseadas em uma história infantil com conteúdo matemático, intitulada Chapeuzinho Vermelho e o 
acordo com o Lobo: 1) abordagem dos conhecimentos e das experiências prévias das participantes, solicitando que elaborassem previsões sobre a história; 2) leitura da história, explorando possibilidades matemáticas; 3) exploração da noção de fração enquanto subconstruto parte-todo (NACARATO et al., 2004), a partir de quantidades discretas e associação dos conteúdos de frações, de números decimais e de porcentagem; 4) elaboração, pelas participantes, da continuação da história, com levantamento de sugestões para a criação de outras situações-problema.

Em um terceiro momento, as participantes, em grupos, criaram uma história em quatro cenas sobre algum conteúdo matemático envolvendo diferentes tipos de problemas. Posteriormente, as professoras socializaram suas produções para as colegas, relatando o processo de produção, justificando de maneira geral a escolha do conteúdo, destacando as ideias que tiveram para abordar o conteúdo, as facilidades e as dificuldades enfrentadas.

O uso de diferentes instrumentos para a produção dos dados - áudio e videogravação do curso, diário de campo e registros produzidos pelas professoras - possibilitou-nos dirigir a atenção para os diversos fenômenos que englobaram o ambiente investigado. Ressaltamos também que os procedimentos metodológicos empregados permitiram a produção de dados descritivos, cuja descrição minuciosa foi útil para uma melhor compreensão da questão estudada, que foi sendo mais bem delineada no decorrer da investigação, por meio de um rico referencial teórico. Além disso, privilegiamos o processo de investigação, e não somente os resultados.

\section{A mobilização das professoras para ensinar matemática}

Nesta seção do artigo apresentaremos os dados, as análises e as discussões sobre a mobilização das professoras no decorrer do curso.

A discussão inicial com as professoras considerou as seguintes temáticas: o ensino da matemática na educação atual, as possibilidades de uma relação de complementaridade entre língua materna e matemática e as potencialidades da utilização dessa relação de integração no ensino e na aprendizagem de matemática. Algumas professoras relataram suas concepções sobre as temáticas abordadas.

Em seguida, enfocamos a discussão na resolução de problemas e no uso de histórias infantis e apresentamos alguns problemas matemáticos ${ }^{1}$. As professoras reuniram-se em grupos para buscar a solução. Posteriormente, realizaram a socialização dos caminhos que percorreram nesse processo. Nessa socialização,

\footnotetext{
${ }^{1}$ Problemas retirados de Smole e Diniz (2001).
} 
expuseram suas ideias, e foi possível discutir conceitos relacionados ao conteúdo específico e verificarmos que elas mobilizaram esses conceitos.

Por exemplo, na situação em que deveriam "montar uma pirâmide de base quadrada usando cinco triângulos isósceles", um grupo concluiu que "não é possivel montar uma pirâmide de base quadrada se os triângulos não forem equiláteros. Não dá para formar a base" (P1)². A partir desse comentário, questionamos se seria possível montar a pirâmide, se fossem triângulos equiláteros. As professoras afirmaram que, mesmo assim, não seria possível, pois "falta um triângulo" (P2). Dessa maneira, concluíram que não existe uma solução para o problema.

Ao buscarem resolver esse problema, as professoras pensaram em formar a base pela justaposição de dois triângulos equiláteros, formando um quadrado e, por isso, estaria faltando um. Então, para verificar se seria mesmo possível formar um quadrado com dois triângulos equiláteros, propusemos que obtivessem um quadrado com dobradura em folha de sulfite. Em seguida, as participantes mediram os lados e também a diagonal, observando que a medida desta última era diferente da medida dos lados e, por isso, dois triângulos equiláteros não formariam um quadrado. As professoras ficaram curiosas para saber que figura seria formada. Novamente, com dobraduras, obtiveram dois triângulos equiláteros e, ao unirem os dois, observaram a formação de um losango.

No segundo problema - construir a planificação de um cubo, dados seis quadrados iguais - as professoras mobilizaram seus conhecimentos específicos para obter mais de uma solução. No entanto, encontraram as soluções mais comumente apresentadas, como mostra a figura 1, a seguir:

Figura 1 - Planificações do cubo
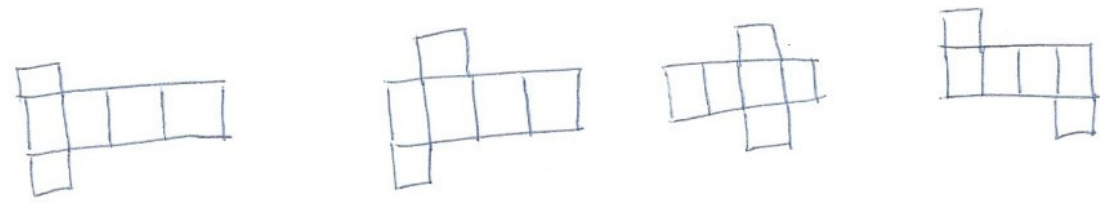

Fonte: Elaboração pelas participantes do curso.

Algumas professoras não tinham conhecimento de que o cubo tem 11 planificações diferentes e, portanto, ficaram surpresas ao saber. Dessa forma, a participação no curso possibilitou seu contato com temáticas várias sobre o ensino e aprendizagem da matemática, algumas das quais não conheciam, fazendo com que ampliassem seus conhecimentos.

$\overline{{ }^{2} \text { Empregamos a letra P }}$ seguida de um número, por exemplo, P1 para identificar cada professora participante do curso. 
No segundo momento do curso, apresentamos uma proposta de atividade de ensino baseada em uma história infantil com conteúdo matemático. Após a leitura da história Chapeuzinho Vermelho e o acordo com o lobo ${ }^{3}$, as professoras resolveram o problema proposto e elaboraram uma continuação para a história. Eis alguns exemplos:

Ao dividir as coxinhas o lobo bradou: "Opa tem coisa errada, você me enganou. Passe-me já essa coxinha que sobrou”. A Chapeuzinho logo defendeu a sua vovó: "Dê essa coxinha a ela seu lobo, tenha dó!'. E a vovó engoliu a coxinha de uma vez só. E agora? Que fração comeu a vovó e sua adorável netinha? (Grupo 2) ${ }^{4}$.

O lobo na divisão achou que a vovó ia ficar prejudicada então ele fez uma contraproposta à Chapeuzinho. Ele ficaria com um terço do total e um terço do restante. Então quantas coxinhas comeram cada um? (Grupo 4).

O lobo ficou com pena da vovó e deu mais uma coxinha para ela. Então os alunos deveriam descobrir a fração. Mas, o lobo ainda ficou faminto, então para evitar problemas ela [vovó] resolveu pedir um bolo e pediu para dividir em 15 pedaços iguais e falou que cada um deveria pegar a mesma quantidade. E o aluno deveria descobrir qual a fração que cada um pegaria (Grupo 6).

Nesse processo, elas mobilizaram o conhecimento do conteúdo específico e o conhecimento pedagógico do conteúdo, pois precisaram pensar sobre os diferentes modos de representação de um conceito e/ou ideia.

O Grupo 2, da mesma forma que na história original, solicitou que fosse descoberta a fração correspondente à quantidade de coxinhas que o lobo, a Chapeuzinho Vermelho e a vovó comeram.

No entanto, nos questionamentos propostos pelo Grupo 4, há uma outra ideia, que é descobrir primeiramente um terço do total de coxinhas e, após, novamente um terço do restante, para saber a fração que o lobo comeu. Depois disso, calcula-se a fração correspondente a quantas coxinhas comeram a Chapeuzinho Vermelho e a vovó.

O Grupo 6 fez uma proposta que se diferencia das anteriores. Como o lobo estava faminto, vovó pediu um bolo que foi dividido em 15 partes iguais, e cada um comeria a mesma quantidade. O professor pode discutir e trabalhar com os alunos o conceito de fração equivalente, pois, no início da história

\footnotetext{
${ }^{3}$ Essa história foi elaborada por uma professora em oficina ministrada no IX Encontro Paulista de Educação Matemática realizado na UNESP-Bauru em 2008. Chapeuzinho Vermelho tenta fazer um acordo com o lobo, sugerindo que dividissem em três partes iguais - para Chapeuzinho, lobo e vovó - as 18 coxinhas que tinha feito, para que não tivesse mais problemas para visitar a vovó. No entanto, o lobo não aceita e quer a metade. A vovó entra na discussão e aceita as condições do lobo, já que ela não come muito e ficará com apenas duas coxinhas. Ao final, a autora propõe questionamentos: Se o lobo ficou com metade e a vovó, com duas coxinhas, que fração comeu a vovó? E sua adorável netinha?

${ }^{4} \mathrm{O}$ lobo queria metade do total de coxinhas que eram 18; portanto, 9 . Então sobraram 9 para dividir entre a vovó e a Chapeuzinho Vermelho, dando 4 para cada uma e sobrando 1 coxinha.
} 
original, Chapeuzinho queria dividir as 18 coxinhas entre os três em partes iguais - cada um comeria $6 / 18$, ou seja, $1 / 3$ das coxinhas. Depois, nos problemas sugeridos por esse grupo, será encontrada a mesma fração - cada um comeria $5 / 15$, ou seja, $1 / 3$ do bolo.

No terceiro momento do curso as professoras elaboram histórias infantis com conteúdos matemáticos. O Quadro 1, a seguir, apresenta uma sinopse do enredo, os conteúdos abordados nas histórias e os problemas propostos ao longo da narrativa.

Quadro 1 - Narrativas elaboradas pelas professoras

\begin{tabular}{|c|c|c|c|}
\hline $\begin{array}{l}\text { Nome do } \\
\text { livro }\end{array}$ & $\begin{array}{l}\text { Conteúdo } \\
\text { matemático }\end{array}$ & Sinopse do enredo & Problemas propostos \\
\hline Família Urso & $\begin{array}{l}\text { 1) Contagem } \\
\text { 2) Combinatória } \\
\text { 3) Divisão }\end{array}$ & $\begin{array}{l}\text { Uma família urso era com- } \\
\text { posta pela mamãe, pelo papai } \\
\text { e por três ursinhos. A mamãe } \\
\text { era muito organizada e arru- } \\
\text { mava as roupas no guarda- } \\
\text {-roupa. O papai era um pouco } \\
\text { bagunçado e deixava as coisas } \\
\text { espalhadas. Um dia eles fize- } \\
\text { ram um piquenique em que } \\
\text { mamãe urso fez bolinhos que } \\
\text { foram divididos entre toda a } \\
\text { família. }\end{array}$ & $\begin{array}{l}\text { 1) Vamos contar quantos } \\
\text { ursos há na família? } \\
\text { 2) Quantas roupinhas estão } \\
\text { guardadas? } \\
\text { 3) Quantas combinações } \\
\text { diferentes podemos fazer } \\
\text { utilizando essas peças? } \\
\text { 4) Quantos brinquedos fi- } \\
\text { caram na estante? E espa- } \\
\text { lhados pelo chão? } \\
\text { 5) No total, quantos brin- } \\
\text { quedos tem no quarto? } \\
\text { 6) Mamãe urso fez } 10 \text { bo- } \\
\text { linhos de chocolate. Quan- } \\
\text { tos bolinhos cada um rece- } \\
\text { berá? }\end{array}$ \\
\hline $\begin{array}{l}\text { Calculando } \\
\text { com João e } \\
\text { Maria }\end{array}$ & $\begin{array}{l}\text { 1) Adição } \\
\text { 2) Divisão } \\
\text { 3) Medidas }\end{array}$ & $\begin{array}{l}\text { João e Maria começaram a } \\
\text { juntar pedrinhas para saírem } \\
\text { em uma aventura caminhando } \\
15 \mathrm{~km} \text {. Depois de juntarem as } \\
\text { pedras durante uma semana, } \\
\text { saíram caminhando e perce- } \\
\text { beram que deixavam } 45 \text { pedri- } \\
\text { nhas em cada quilômetro. As } \\
\text { pedrinhas não deram para eles } \\
\text { caminharem todo o percurso. } \\
\text { Mesmo assim, ficaram felizes } \\
\text { e resolveram juntar o dobro } \\
\text { de pedrinhas para a próxima } \\
\text { aventura. }\end{array}$ & $\begin{array}{l}\text { 1) João e Maria juntaram } \\
\text { pedrinhas e estavam com } \\
\text { dificuldades para contá-las. } \\
\text { Vamos auxiliá-los a contá- } \\
\text {-las? } \\
\text { 2) Dividiram igualmente as } \\
\text { pedrinhas. Quantas pedri- } \\
\text { nhas ficaram com cada um? } \\
\text { 3) Em cada quilômetro gas- } \\
\text { taram } 45 \text { pedrinhas. Quan- } \\
\text { tos quilometros consegui- } \\
\text { ram percorrer com a quan- } \\
\text { tidade de pedrinhas? }\end{array}$ \\
\hline
\end{tabular}




\begin{tabular}{|c|c|c|c|}
\hline $\begin{array}{l}\text { Nome do } \\
\text { livro }\end{array}$ & $\begin{array}{l}\text { Conteúdo } \\
\text { matemático }\end{array}$ & Sinopse do enredo & Problemas propostos \\
\hline $\begin{array}{l}\text { O terreno } \\
\text { dos três } \\
\text { porquinhos }\end{array}$ & $\begin{array}{l}\text { 1) Medida } \\
\text { (padronização das } \\
\text { medidas) } \\
\text { 2) Área } \\
\text { 3) Divisão }\end{array}$ & $\begin{array}{l}\text { Os três porquinhos ganharam } \\
\text { um terreno para ser dividido } \\
\text { entre eles. Um porquinho me- } \\
\text { diu usando uma fita métrica; } \\
\text { outro, usando uma vara; e o } \\
\text { último, dando passos para } \\
\text { medir os lados do terreno. } \\
\text { Discutiram qual forma de } \\
\text { medir era melhor e chegaram } \\
\text { à conclusão de que, indepen- } \\
\text { dentemente da forma como } \\
\text { seria dividido o terreno, todos } \\
\text { receberiam o terreno de mes- } \\
\text { mo tamanho. }\end{array}$ & $\begin{array}{l}\text { Qual o tamanho do terreno } \\
\text { que ficou para cada um? }\end{array}$ \\
\hline $\begin{array}{l}\text { O } \\
\text { piquenique } \\
\text { da família } \\
\text { peixe }\end{array}$ & 1) Multiplicação & $\begin{array}{l}\text { Uma família peixe, composta } \\
\text { pela mamãe, pelo papai, por } \\
\text { três filhos e pela avó, se ali- } \\
\text { mentava quatro vezes por dia. } \\
\text { Cada um comia uma quanti- } \\
\text { dade diferente de diversos ali- } \\
\text { mentos. Um dia foram fazer } \\
\text { um piquenique e precisavam } \\
\text { descobrir quanta comida de- } \\
\text { veriam levar porque fariam } \\
\text { três refeições fora de casa. } \\
\text { As autoras pedem a ajuda do } \\
\text { leitor para descobrir a quanti- } \\
\text { dade de comida. }\end{array}$ & $\begin{array}{l}\text { 1) Quantos peixinhos } \\
\text { mamãe-peixe precisa pre- } \\
\text { parar para ela e toda sua } \\
\text { família, para o pique- } \\
\text { nique? } \\
\text { 2) Qual o total de alimen- } \\
\text { tos que ela terá que prepa- } \\
\text { rar par seus filhos? } \\
\text { 3) Desenhe os alimentos } \\
\text { da cena } 2 \text {. }\end{array}$ \\
\hline $\begin{array}{l}\text { Os } \\
\text { porquinhos } \\
\text { e a divisão }\end{array}$ & $\begin{array}{l}\text { 1) Fração } \\
\text { 2) Divisão }\end{array}$ & $\begin{array}{l}\text { Três porquinhos estavam pas- } \\
\text { seando pela floresta e viram } \\
\text { uma árvore cheia de frutas. O } \\
\text { porquinho mais velho queria } \\
\text { metade das frutas para ele, } \\
\text { mas os outros contestaram, } \\
\text { porque queriam que a divi- } \\
\text { são fosse realizada em partes } \\
\text { iguais. Depois de contarem a } \\
\text { quantidade de frutas, solici- } \\
\text { taram ao leitor como deveria } \\
\text { ser a divisão. }\end{array}$ & $\begin{array}{l}\text { Como eles dividirão } 20 \\
\text { frutas em partes iguais? }\end{array}$ \\
\hline
\end{tabular}


(conclusão)

\begin{tabular}{|c|c|c|c|}
\hline $\begin{array}{l}\text { Nome do } \\
\quad \text { livro }\end{array}$ & $\begin{array}{l}\text { Conteúdo } \\
\text { matemático }\end{array}$ & Sinopse do enredo & Problemas propostos \\
\hline $\begin{array}{l}\text { Final de } \\
\text { semana }\end{array}$ & $\begin{array}{l}\text { 1) Multiplicação } \\
\text { 2) Sistema } \\
\text { monetário } \\
\text { 3) Ideia de } \\
\text { dobro, dúzia, } \\
\text { unidades } \\
\text { 4) Divisão } \\
\text { 5) Fração }\end{array}$ & $\begin{array}{l}\text { Antonio e sua família foram } \\
\text { passar o fim de semana no } \\
\text { sítio de sua avó, Alice, e seu } \\
\text { avô, Júlio. Resolveram fa- } \\
\text { zer um churrasco e Antonio } \\
\text { comprou } 5 \mathrm{~kg} \text { de picanha, } 3 \\
\text { kg de linguiça e } 2 \mathrm{~kg} \text { de asa } \\
\text { de frango. Na história é apre- } \\
\text { sentada uma tabela com os } \\
\text { preços de cada item. Sua avó } \\
\text { Alice estava preparando um } \\
\text { bolo e, como toda família es- } \\
\text { taria presente, percebeu que } \\
\text { apenas um bolo não daria e } \\
\text { resolveu dobrar a quantidade } \\
\text { dos ingredientes da receita } \\
\text { (é apresentada a receita do } \\
\text { bolo). Alice pediu aos netos } \\
\text { que colhessem algumas frutas } \\
\text { no pomar (2 dúzias de laran- } \\
\text { jas, } 10 \text { unidades de maças, } 3 \\
\text { dúzias de mexericas e } 3 \text { li- } \\
\text { mões). O churrasco foi uma } \\
\text { delícia e vovó dividiu o bolo } \\
\text { em } 20 \text { pedaços bem grandes } \\
\text { para que todos pudessem co- } \\
\text { mer. }\end{array}$ & $\begin{array}{l}\text { As autoras não propõem } \\
\text { problemas. }\end{array}$ \\
\hline
\end{tabular}

Fonte: Os autores.

Observando as discussões das participantes em cada grupo no momento de elaborarem os livros e considerando os depoimentos das professoras ao final do curso, verificamos que, ao elaborarem as narrativas, as professoras precisaram pensar sobre o conteúdo matemático, sobre as maneiras de expô-lo aos alunos e sobre os problemas propostos.

Além disso, elas mobilizaram elementos referentes ao conhecimento pedagógico do conteúdo, ou seja, para elaborarem o material, as professoras precisaram levantar possibilidades sobre quais seriam os conhecimentos dos alunos, suas reações à narrativa e aos problemas, o comportamento que poderiam ter, suas possíveis dificuldades de compreensão do conteúdo e o modo como o professor pode lidar com isso.

Os exemplos expostos a seguir mostram algumas mobilizações: 
Não pensamos em "fechar" as informações, por exemplo, quando colocamos a tabela da carne [na página 2] podíamos apenas pedir somente isso para o aluno. Mas assim está restringindo, em cada sala tem uma realidade diferente, a professora pode falar "os pais tinham 100 reais. Que associação pode fazer. O que agente poderia estar comprando?”. Então surge a ideia de cada sala. E no final em que o bolo é dividido, para que todas as pessoas comessem a vontade, podemos colocar para o aluno "quantas pessoas você imagina?". Na questão da receita agente está trabalhando quantidade. Trabalhar com medidas, na prática, fica mais fácil para a criança entender. (Grupo 6).

Pensamos que o professor pode fazer vários questionamentos durante a leitura focando os conteúdos. Possíveis intervenções: a partir de uma situação problema apresentada pelo professor ele poderia perguntar aos alunos "o que vocês acham que os porquinhos vão usar para medir o terreno?”, e aí o professor faz um levantamento das hipóteses que as crianças têm de medidas e poderiam aparecer outras diferentes das que elencamos. $\mathrm{Na}$ sala de aula o professor pode elencar outras medidas das que colocamos aqui [no livro]. (Grupo 5).

Além disso, as participantes relataram que tiveram a preocupação de elaborar narrativas interessantes aos alunos, que pudessem proporcionar desafios possíveis de serem solucionados, enredos que possibilitassem o diálogo do professor com os alunos sobre os conteúdos, como é possível observar em alguns depoimentos:

Tivemos preocupação com a faixa etária, no sentido de propor os problemas que fossem desafiantes, mas possiveis de resolver (P1).

Elaborar uma história em que o professor pode fazer vários questionamentos durante a leitura focando os conteúdos (P2).

Não pensamos em "fechar" as informações. No final em que o bolo é divido para que todas as pessoas comessem à vontade, e podemos colocar para o aluno "quantas pessoas ele imagina" (P3).

As histórias também foram ilustradas, e as professoras utilizaram muita criatividade. Por exemplo, na narrativa Família Urso, é possível abrir o guarda-roupa e verificar quantas peças de roupa há dentro dele.

No entanto, duas ocorrências deixaram clara a importância do cuidado a ser tomado na elaboração das ilustrações: na narrativa Calculando com João $e$ Maria, uma figura revela duas caixas contendo algumas pedras, mas sua quantidade não corresponde ao total de pedras que os dois personagens juntaram. Esse fato pode levar o aluno a não saber que quantidade de pedras deve utilizar para ajudá-los a contar, como solicitado em um dos problemas. O mesmo acontece na narrativa Os porquinhos e a divisão, pois, na ilustração da árvore, há 17 frutas e, no enunciado do problema, é questionado como dividirão em partes iguais 20 frutas entre os três porquinhos. 
Figura 2 - Ilustração dos livros "Calculando com João e Maria" e "Os porquinhos e a divisão" respectivamente

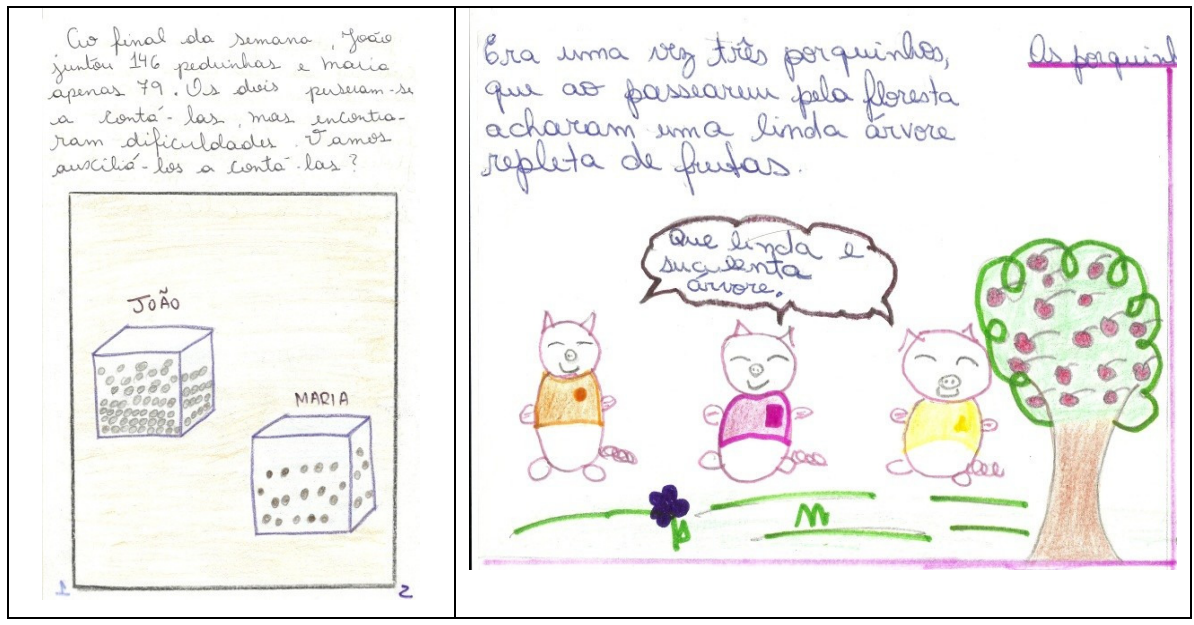

Fonte: Elaboração pelas professoras participantes do curso.

Diante desses dados, é importante ressaltar que as ilustrações, as imagens das histórias infantis enriquecem a imaginação do leitor e, no caso da conexão literatura-matemática, podem, se elaboradas de forma coerente com o texto,auxiliar o aluno a compreender um conceito ou uma ideia matemática.

Dalcin (2002, p. 63), ao investigar a "proposta de articulação entre a simbologia matemática, as imagens entendidas como ilustrações e o texto escrito", verificou que essas três dimensões podem estar ou não totalmente articuladas em um livro paradidático e criou algumas categorias relativas às imagens e à articulação delas com o texto escrito e/ou com a simbologia matemática: ilustrações imbricadas, nas quais os três elementos estão relacionados; ilustrações ornamentais, em que os três elementos não se articulam; ilustrações de visualização, em que essas imagens estão articuladas apenas à simbologia matemática; ilustrações de contextualização, nas quais as imagens se conectam com o texto escrito, complementando-o e auxiliando na interpretação.

De acordo com a autora, a história que apresentar articulação entre os três elementos - simbologia matemática, texto escrito e imagem - proporcionará ao leitor maior compreensão do que lê e dos conceitos matemáticos abordados na história.

As ilustrações poderão facilitar o processo de compreensão do conteúdo matemático sob vários aspectos, principalmente como meio pelo qual se incentiva a visualização e o processo imaginativo. Porém, é necessário coerência entre o que está sendo dito por meio do texto escrito e da simbologia 
matemática e o que está sendo representado nas imagens [...]. (DALCIN, 2002, p. 64).

Dessa forma, é muito importante, ao elaborar uma história com conteúdo matemático,que se atente às ilustrações, pois elas podem auxiliar a compreensão do texto e a compreensão do conhecimento matemático abordado ou - caso não estejam claras - provocar confusões.

Continuando a discussão referente à mobilização de conhecimentos do conteúdo específico, é importante registrar que as professoras que elaboraram a narrativa $O$ terreno dos três porquinhos mobilizaram seus conhecimentos do conteúdo matemático, ao manterem a proporcionalidade das medidas utilizadas, pois cada porquinho mediu o terreno com um instrumento diferente - fita métrica, vara, passos - e, por exemplo, ao calcular a área total do terreno medido com passos, o valor obtido foi maior do que quando calculado com a fita métrica, porque o passo do porquinho é menor que um metro, ou seja, ele precisou dar mais passos para verificar as medidas dos lados do terreno. $\mathrm{O}$ mesmo acontece com a vara.

Com exceção de um texto - O piquenique da família peixe -, todos abordam mais de um conteúdo matemático, um dos quais é operações aritméticas. Dois dos textos envolvem medidas; dois outros apresentam frações; um deles envolve ideias de combinatória; outro trabalha com sistema monetário; e outro, ainda, aborda área do retângulo.

Dessa forma, questionamo-nos: por que a maioria das professoras aborda as operações aritméticas? Talvez por terem o domínio desses conteúdos e, por isso, se sentirem mais seguras para utilizá-los, o que pode não ocorrer com os outros conteúdos, como a geometria e o tratamento da informação.

Tal insegurança pode talvez ser explicada pelo fato de não se ensinarem esses conteúdos nos cursos de formação, pois, como evidencia a investigação de Curi (2005) sobre a formação matemática dos professores dos anos iniciais do Ensino Fundamental,as ementas das disciplinas dão destaque à construção do número e às quatro operações e muito raramente indicam o ensino de geometria e o tratamento da informação.

Além disso, as professoras estavam em uma situação que não lhes era habitual, criando histórias infantis com conteúdos matemáticos, e isso não é tão simples, devido aos diferentes fatores que elas apontaram ter observado - a faixa etária, os problemas propostos, etc. Por isso, a escolha de conteúdos dos quais tinham domínio pode ser um indício de que preferem estar seguras do que abordam, o que possibilita ficarem na zona de conforto que lhes dá segurança e certo nível de controle da situação. 
Outra questão que discutiremos aqui diz respeito aos problemas propostos,inseridos ao longo das histórias,para os quais as professoras também tiveram que mobilizar seus conhecimentos. Apenas as autoras do livro Final de semana não propuseram problemas, o que não quer dizer que isso não possa ser explorado pelo professor, pois a história elaborada permite abordar inúmeros problemas.

Por não terem a prática de elaborar problemas para propor a seus alunos em sua rotina de aulas,pois, de maneira geral, apresentam problemas retirados de fontes disponíveis, como, por exemplo, o livro didático, a formulação de problemas pelas professoras não foi um processo simples e fácil. Contudo, compreendemos que a metodologia de resolução de problemas é muito importante e pode ser explorada nessa conexão com as histórias infantis.

De acordo com os Parâmetros Curriculares Nacionais de Matemática (BRASIL, 1997), a resolução de problema é uma orientação para a aprendizagem, pois existe um contexto a partir do qual o aluno irá aprender as ideias, as concepções, os procedimentos que englobam os diversos conhecimentos da área de matemática. Esse documento assinala também que o foco da resolução de problemas não é o resultado, mas, sim, o processo de resolução dos problemas. Assim, o ponto de partida é o próprio problema que deve ser explorado pelos alunos, pois eles próprios irão elaborar as estratégias necessárias para a solução do questionamento.Afinal, “[...] o aluno não constrói um conceito em resposta a um problema, mas constrói um campo de conceitos que tomam sentido num campo de problemas. Um conceito matemático se constrói articulado com outros conceitos, por meio de uma série de retificações e generalizações" (BRASIL, 1997, p. 31).

Sendo assim, o documento oficial preconiza a proposta de problemas que possibilitem a construção do conhecimento e de conceitos específicos. Podemos tecer uma crítica a essa perspectiva no PCN, considerando o apontamento de Onuchic (1999) de que a resolução de problemas acaba sendo concretizada do seguinte modo: o "ensino-aprendizagem de um tópico matemático começa com uma situação-problema que expressa aspectos-chave desse tópico e são desenvolvidas técnicas matemáticas como respostas razoáveis para problemas razoáveis" (ONUCHIC, 1999, p. 207).

Contudo, para Onuchic e Allevato (2004), o foco do ensino de matemática deve ser a compreensão. Segundo as autoras,

[...] a compreensão de Matemática, por parte dos alunos, envolve a ideia de que compreender é essencialmente relacionar. Esta posição baseia-se na observação de que a compreensão aumenta quando o aluno é capaz de: relacionar uma determinada ideia matemática a um grande número ou a uma variedade de contextos, relacionar um dado problema a um grande número 
de ideias matemáticas implícitas nele, construir relações entre as várias ideias matemáticas contidas num problema. (ONUCHIC; ALLEVATO, 2004, p. 222).

Essa perspectiva revela que a matemática não se limita a ser uma simples ferramenta para resolver problemas, mas é um caminho de pensar e um organizador de experiências (ONUCHIC, 1999).

Com o foco na compreensão, a resolução de problemas se torna uma atividade para aquisição de um novo conhecimento e um processo que possibilita aplicar algo anteriormente construído. Afinal, para Onuchic (1999, p. 208), "quando os professores ensinam matemática através da resolução de problemas, eles estão dando a seus alunos um meio poderoso e muito importante de desenvolver sua própria compreensão".

De acordo com Onuchic e Allevato (2004), trabalhar com resolução de problemas possibilita que o aluno atente para as ideias inerentes ao problema, ou que se conecte a ele, reflita sobre elas e busque "dar sentido" à situação, assim como proporciona que o aluno se envolva nos seguintes procedimentos: raciocínio e prova, comunicação, conexões e representações. Outro apontamento das autoras se refere ao fato de que os problemas podem oferecer dados importantes para avaliar a aprendizagem dos alunos e, a partir disso, o professor pode reorganizar as situações de ensino e aprendizagem.

Alguns problemas propostos nas histórias elaboradas trazem em seu enunciado os dados necessários para sua resolução, enquanto outros exigem que os alunos observem as ilustrações para encontrar os dados. No entanto, de maneira geral, todos os problemas propostos podem ser considerados convencionais ou padrão, isto é, contêm frases e parágrafos curtos; oferecem "pistas" para a(s) operação(s) a ser efetuada(s); indicam, no enunciado do problema,todos os dados necessários para sua resolução; apresentam uma única solução; a solução é numérica e é encontrada a partir da aplicação direta de algoritmos (SMOLE; DINIZ, 2001).

É importante que o professor não se limite a propor aos alunos problemas do tipo convencional e aborde situações que, sem solução aparente, requerem a busca e a seleção de estratégias e conhecimentos. Um problema que não seja do tipo convencional ou padrão é aquele que instiga o aluno, permitindo que ele crie, reflita e teste diversas hipóteses de solução, “[...] sob esse enfoque, resolver problemas é um espaço para fazer colocações, comunicar ideias, investigar relações, é um momento para desenvolver noções e habilidades matemáticas." (SMOLE et al., 2004, p. 7). 
Stancanelli (2001) apresenta diferentes tipos de problemas: problema sem solução, problemas com mais de uma solução, problemas com excesso de dados, problemas de lógica,de estratégia, entre outros.

Em um problema sem solução, a impossibilidade de solucioná-lo provém de vários aspectos, como a inexistência de dados para resolver o problema, a presença de uma pergunta inadequada ou ainda uma impossibilidade matemática.

Em contrapartida, há problemas que permitem diversas soluções, rompendo com a ideia de que o problema matemático deve possuir uma apenas uma solução e que esta implica uma única maneira de ser realizada. Na perspectiva de Stancanelli (2001, p. 109), "O trabalho com problemas com duas ou mais soluções faz com que o aluno perceba que resolvê-los é um processo de investigação do qual ele participa como ser pensante e produtor de seu próprio conhecimento".

Outro tipo de problema não convencional é aquele que possui dados numéricos ou não - que não são necessários para a resolução do problema. Esse excesso de dados mostra para o aluno a importância de ler atentamente o problema, bem como a necessidade de selecionar trechos e dados relevantes para a solução.

Diferentes dos demais, os problemas de lógica exigem raciocínio dedutivo, e sua resolução não é numérica. Eles "propiciam uma experiência rica para o desenvolvimento de operações de pensamento como previsão e checagem, levantamento de hipóteses, busca de suposições, análise e classificação" (STANCANELLI, 2001, p. 114).

Enfatizamos que a importância de trabalhar com a variedade de problemas está em possibilitar ao aluno desenvolver uma postura de investigação e autonomia ao resolver os problemas, "tornando-se um indivíduo capaz de enfrentar, observar, discutir e deduzir os desafios, perseverando na busca de caminho para possíveis soluções” (STANCANELLI, 2001, p. 120).

Ao longo do processo de elaboração das histórias e das ilustrações, da escolha do conteúdo matemático e dos problemas propostos, as professoras se colocaram em movimento, envolvendo-se na atividade, e mobilizaram os diferentes conhecimentos necessários para alcançarem o objetivo esperado.

\section{Algumas considerações}

Neste artigo tivemos como objetivo identificar os conhecimentos mobilizados por professoras dos anos iniciais do Ensino Fundamental, ao elaborarem histórias infantis com conteúdo matemáticos. 
Para tanto, as professoras participaram de um curso de curta duração, denominado Chapeuzinho Vermelho, Lobo e Frações: histórias nas aulas de matemática, no qual discutimos o ensino da matemática na educação atual, as possibilidades de uma relação de complementaridade entre língua materna e matemática, as potencialidades da utilização dessa relação de integração no ensino e na aprendizagem de matemática, a resolução de problemas e o uso de histórias infantis.

Dessa forma, o envolvimento na resolução de problemas não convencionais e as discussões sobre os conteúdos matemáticos foram momentos em que as professoras se mobilizaram trazendo à tona seus conhecimentos do conteúdo e pedagógicos do conteúdo. No entanto, os problemas formulados pelas participantes nas histórias infantis são do tipo convencional ou padrão, o que demonstra que as práticas não são simples de serem modificadas e necessitam de fortes abalos para que isso aconteça. Na formação docente, discussões como as ocorridas no curso podem se juntar a outras reflexões já realizadas ou ainda por vir, promovendo pequenas mudanças que, talvez com o tempo e com o desenvolvimento profissional docente, levem a grandes transformações.

Além disso, no curso,as professoras puseram-se em movimento para realizar atividades que não fazem parte de sua rotina de trabalho e que também podem ter promovido reflexões acerca do ensino de matemática, como a formulação de problemas e a elaboração de histórias infantis com conteúdo matemático. E essa experiência é positiva, pois pode tornar-se um ponto de partida para novas aprendizagens.

A preocupação com a forma de abordar o conteúdo, com a faixa etária, com as ilustrações, com a escrita da história fez com que mobilizassem seus conhecimentos do conteúdo e seus conhecimentos pedagógicos do conteúdo, de forma a elaborar uma história com muitas possibilidades de exploração e com grande potencialidade para o ensino dos conteúdos abordados.

Desse modo, a participação no curso possibilitou que as professoras se mobilizassem, questionassem, refletissem, trocassem ideias nos grupos, compartilhassem experiências, expusessem suas compreensões e suas concepções, se surpreendessem com algumas ideias que não conheciam.

\section{Referências}

BRASIL. Secretaria de Educação Fundamental. Parâmetros Curriculares Nacionais: Matemática. Brasília: MEC/SEF, 1997.

CAREY, D. The patchwork quilt: a context for problem solving. Arithmetic Teacher, v. 39, n. 4, p.199-203, dez. 1992. 
CARNEIRO, R. F.; PASSOS, C. L. B. Matemática e literatura infantil: uma possibilidade para quebrar a armadilha do desconhecimento matemático. In: CONGRESSO DE LEITURA DO BRASIL - COLE, 16., 2007, Campinas. Anais... Campinas: UNICAMP, 2007. p. 1-10.

CHARLOT, B. Da relação com o saber: elementos para uma teoria. Porto Alegre: Artmed, 2000.

CURI, E. A formação matemática de professores dos anos iniciais do ensino fundamental face às novas demandas brasileiras. Revista Iberoamericana de Educação, v. 37, n. 5, p. 1-10, 2005. Disponível em: <http://www.rieoei.org/deloslectores/1117Curi.pdf> Acesso em: 28 jul. 2011.

DALCIN, A. Um olhar sobre o paradidático de matemática. 2002. 162 f. Dissertação (Mestrado em Educação Matemática) - Faculdade de Educação, Universidade de Campinas, Campinas, 2002.

DEMO, P. Pesquisa participante: mito e realidade. Rio de Janeiro: Senac, 1984.

GAILEY, S. K. The mathematics children's connection. Arithmetic Teacher, v. 40, n. 5, p. 258-259, jan. 1993.

GÓMEZ-GRANELL, C. A aquisição da linguagem matemática: símbolo e significado. In: TEBEROSKY, A.; TOLCHINSKY, L. (Org.). Além da alfabetização: a aprendizagem fonológica, ortográfica, textual e matemática. São Paulo: Ática, 1997. p. 257-282.

KLIMAN, M.; RICHARDS, J. Writing, sharing and discussing mathematics stories. Arithmetic Teacher, v. 38, n. 3, p. 138-141, nov. 1992.

MACHADO, N. J. Matemática e língua materna: a análise de uma impregnação mútua. 5. ed. São Paulo: Cortez, 2001.

MIZUKAMI, M. G. N. Aprendizagem da docência: algumas contribuições de L. S. Shulman. Educação, v. 29, n. 2, 2004. Disponível em: <http://coralx.ufsm.br/revce/revce/2004/02/ a3.htm>. Acesso em: 1 ago. 2008.

NACARATO, A. M. et al. Números racionais: aspectos conceituais, o papel da linguagem e dos materiais manipulativos. Horizontes, Bragança Paulista, v. 22, n. 1, p. 53-64, jan./jun. 2004.

NEUENFELDT, A. E. Matemática e literatura infantil: sobre os limites e possibilidades de um desenho curricular interdisciplinar. 2006. 194 f. Dissertação (Mestrado em Educação) - Centro de Educação, Universidade Federal de Santa Maria, Santa Maria, 2006.

ONUCHIC, L. R. Ensino-aprendizagem de Matemática através da resolução de problemas. In: BICUDO, M. A. V. (Org.). Pesquisa em Educação Matemática: concepções e perspectivas. São Paulo: UNESP, 1999. p. 199-220.

ONUCHIC, L. R.; ALLEVATO, N. S. G. Novas reflexões sobre o ensino-aprendizagem de matemática através da resolução de problemas. In: BICUDO, M. A. V.; BORBA, M. C. (Org.). Educação Matemática: pesquisa em movimento. São Paulo: Cortez, 2004. p. 199-218.

PASSOS, C. L. B.; OLIVEIRA, R. M. M. A.; GAMA, R. P. Grupo de estudo colaborativo: matemática conectada com histórias infantis promovendo desenvolvimento profissional. In: ENCONTRO NACIONAL DE EDUCAÇÃO MATEMÁTICA, 9., 2007, Belo Horizonte. Anais... Belo Horizonte: SBEM, 2007. p. 1-17. 
SHULMAN, L. Those who understand: knowledge growth in teaching. In: WILSON, S. M. (Ed.).The wisdom of pratice: essays on teaching, learning and learning to teach. United States of America: Jossey-Bass, 2004, p. 189-215.

SILVA, A. C. Matemática e literatura infantil: um estudo sobre a formação do conceito de multiplicação. 2003. 189 f. Dissertação (Mestrado em Educação) - Centro de Educação, Universidade Federal da Paraíba, João Pessoa, 2003.

SMOLE, K. C. S.; DINIZ, M. I. (Org.). Ler, escrever e resolver problemas: habilidades básicas para aprender matemática. Porto Alegre: Artmed, 2001.

SMOLE, K. C. S.; ROCHA, G. H. R.; CANDIDO, P. T.; STANCANELLI, R. Era uma vez na matemática: uma conexão com a literatura infantil. 5. ed. São Paulo: IME-USP, 2004.

SOUZA, A. P. G. Histórias infantis e matemática: a mobilização de recursos, a apropriação de conhecimentos e a receptividade de alunos de $4^{\mathrm{a}}$ série do ensino fundamental. 2008. 207 f. Dissertação (Mestrado em Educação) - Centro de Educação e Ciências Humanas, Universidade Federal de São Carlos, São Carlos, 2008.

STANCANELLI, R. Conhecendo diferentes tipos de problemas. In: SMOLE, K. S.; DINIZ, M. I. (Orgs.). Ler, escrever e resolver problemas: habilidades básicas para aprender matemática. Porto Alegre: Artmed, 2001. p. 103-120.

WELCHMAN-TISCHER, R. How to use children's literature to teach mathematics. Reston: NCTM, 1992.

Recebido em 19/03/2012

Aceito em 10/09/2012 